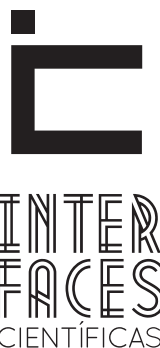

EDUCAÇÃO

ISSN IMPRESSO 2316-333X

ISSN ELETRÔNICO 2316-3828

\title{
PROJETO DE PESQUISA: \\ FASE CRUCIAL PARA O SUCESSO DE UMA INVESTIGAÇÃO CIENTÍFICA
}

Maria de Fátima Nascimento ${ }^{1}$

Kathia Cilene Santos Nascimento
Hortência de Abreu Gonçalves²

\section{RESUMO}

No âmbito do ensino superior, a prática da investigação científica necessita da elaboração do projeto de pesquisa, como roteiro que distribui as etapas de sua realização. Objetivou-se descrever o projeto de pesquisa e sua importância no âmbito da construção do conhecimento. Para tanto, recorreu-se ao levantamento de fontes secundárias, bem como a órgãos oficiais de pesquisa, a exemplo do Conselho Nacional de Desenvolvimento Científico e Tecnológico (CNPQ) e Conselho de Aperfeiçoamento de Pessoal de Ensi- no Superior (CAPES). Nesta fase da educação, tem destaque a inquietação e a curiosidade surgidas em decorrência das novas descobertas científicas. Este processo ocorre mediante procedimento racional, sistemático e crítico, visando à prática investigativa.

\section{PALAVRAS-CHAVE}

Pesquisa Científica. Projeto de Pesquisa. Etapas da Investigação. 


\section{ABSTRACT}

Within higher education, the practice of scientific research requires the development of the research project, as script which distributes the steps of its realization. This study aimed to describe the research project and its importance in the construction of knowledge. Therefore, we resorted to the survey from secondary sources, as well as the official research, such as the National Council for Scientific and Technological Development (CNPq) and Council for the Improvement of Higher Education Personnel (CAPES). At this stage of education has highlighted the unease and curiosity arose as a result of new scientific discoveries. This process occurs by rational, systematic and critical procedure in order to research practice.

\section{KEYWORDS}

Scientific research. Research project. Research steps.

\section{INTRODUÇÃO}

A sistematização o processo da pesquisa científica e consequentemente a elaboração do projeto de pesquisa que é um documento que descreve os planos, fases e procedimentos de um processo de investigação científica a ser realizado. Segundo Gil (2002 p. 21) "é o processo sistematizado, mediante o qual se pode conferir maior eficiência à investigação para em determinado prazo alcançar o conjunto das metas estabelecidas". É ainda, a primeira etapa componente de um plano, de um empreendimento ou de um processo de elaboração, execução e apresentação do assunto ou tema, que se propõe o que se quer pesquisar. Lembrando, porém, que para elaboração de projeto de

\section{RESUMEN}

En la educación superior, la práctica de la investigación científica requiere el desarrollo del proyecto de investigación, un script que distribuye los pasos de su realización. Este estudio tuvo como objetivo describir el proyecto de investigación y su importancia en la construcción del conocimiento. Para Ello, si uso su estudio de fuentes secundarias, como ASI cuerpos los Oficiales de Investigación, cuentos de como el Consejo Nacional de Desarrollo de Desarrollo Científico y Tecnológico (CNPq) y el Consejo Para La Mejora Personal de Nivel Superior (CAPES). En esta etapa de la educación, se ha puesto de manifiesto la inquietud y la curiosidad surgidasem debido a los nuevos descubrimientos científicos. Este proceso se produce a través del procedimiento racional, sistemática y crítica, orientada a la práctica de la investigación.

\section{PALABRAS-CLAVE}

La investigación científica. Proyecto de investigación. Etapas de la investigación.

pesquisa é necessário seguir a NBR 15287 - Associação de Normas Técnicas (ABNT), devendo considerar os passos que devem ser seguidos para que a pesquisa seja bem sucedida, onde o projeto servirá de guia para sua execução (ABNT NBR 15287, 2006).

Nessa fase, portanto, o trabalho a ser realizado já deve ter um título definido, "cartão de apresentação" do projeto de pesquisa, que parte do tema, expressando a delimitação e a abrangência temporal e espacialdo que se pretende pesquisar, ou seja, o pesquisador obviamente já possui uma visão abrangente do projeto que irá executar. 
Consequentemente, alguns passos deverão ser seguidos na elaboração do Projeto de Pesquisa, em que sua apresentação deverá seguir uma diretriz pré-definida contendo elementos considerados fundamentais para uma boa execução. Esses elementos, segundo Cooper e Shindler (2003),compõem-se de

[...] clareza, organização, em termos de lógica e fácil compreensão, total atendimento das especificações da solicitação de proposta, incluindo orçamento e programação, estilo de redação apropriado e submissão dentro do prazo da solicitação de proposta. Isto significa a necessidade de um compromisso efetivo no que diz respeito à pesquisa.

0 projeto de pesquisa se compõe dos seguintes elementos: pré-textuais que são capa, folha de rosto, sumário. Os textuais: introdução, tema, problema, justificativa, objetivos, hipóteses ou questões norte- adoras, fundamentação referencial teórica, procedimentos metodológicos orçamento e os pós-textuais que compõe, as referências, os apêndices, anexos.

A capa é um dos elementos que deve conter o nome da instituição e do curso; nome do autor do trabalho; título, e subtítulo (se houver); local e ano da conclusão.

Na Folha de Rosto deve constar o nome do autor; título do trabalho, e subtítulo (se houver); caracterizando o objetivo do trabalho; o nome da instituição a que é submetido; nome do orientador, local (cidade) da instituição onde deve ser apresentado; e o ano. 0 Sumário é um elemento obrigatório. Nele você deve enumerar as partes doprojeto de pesquisa, acompanhadas das respectivas páginas.

\section{PROJETO: CONFIGURAÇÃO DA PESQUISA CIENTÍFICA}

Inicialmente se procede à escolha do Tema da Pesquisa é o assunto que se deseja estudar e pesquisar e partir preferencialmente da afinidade do pesquisador, como, por exemplo, de seu contexto social, profissional ou cultural em que, sua escolha deve levar em conta possibilidades, aptidões e tendências de quem irá elaborar a pesquisa. Para isso, é preciso ter consciência de que o intuito de qualquer pesquisa é abrir caminhos para o avanço do conhecimento, integrando novas descobertas com base em diferentes abordagens agregando a criatividade do pesquisador, promovendo novas visões no campo da pesquisa.

O tema de uma pesquisa indica uma área de interesse a ser investigada, se faz necessário, portanto, um recorte mais "concreto", mais preciso deste assunto. Ele deverá ser delimitadotornando-o compreensível quanto à área específica do conhecimento, o espa- ço geográfico da abrangência da pesquisa e o período focalizado na pesquisa. Lembrando, porém, que essa escolha, não se faz aleatoriamente, demanda tempo, para uma decisão consciente daquilo que se quer pesquisar. Por isso, não existe receita pronta e acabada para se definir um tema. Porém, é necessário que se estabeleça alguns pontos para otimizar o tempo e evitar problemas futuros durante a execução do projeto, considerando que este deve ser flexível e adaptado a especificidade da pesquisa e as suas finalidades.

É necessário que se busque um apoio e o respaldo técnico e científico que farão grande diferença seu projeto. Deve-se procurar escolher um tema que se goste e se identifique, pois isso ajudará no desenvolvimento de um trabalho mais prazeroso e eficiente. Mediante esse procedimento, procure-se ter um conhecimento mais aprofundado do tema escolhido, 
fazendo leituras previamente estabelecidas, que irão colaborar na construção do ponto de partida para os questionamentos. Não se deve esquecer-se de verificar a relevância do tema escolhido, e a sua contribuição para o avanço no campo determinado.

Existem alguns critérios para a escolha adequada de um tema de pesquisa que deverão ser respeitados para um bom resultado final. 0 gosto pessoal, ou seja, um tema em que a preferência do pesquisador gera empatia, entusiasmo e favorece a perseverança; o preparo técnico envolve a formação cultural e a vivência pessoal às quais garantirão o início bem sucedido do processo de busca. Outro critério bastante importante é o tempo disponível que garantirá a continuidade do processo até o ponto desejado. Não se esquecendo, porém, que a escolha de um tema para o desenvolvimento de uma pesquisa deve atender a estes objetivos básicos: gostar do assunto, ter acesso a informações e dados necessários, ter tempo e outras condições materiais necessárias e que tal tema seja de interesse social.

De posse do tema escolhido e delimitado, é hora de realizar a caracterização do problema que deverá estar relacionado ao tema, ou seja, uma questão associada ao tema com importância real, e que ainda não tenha sido devidamente respondida pela literatura existente, e que focaliza o que vai ser investigado dentro do tema da pesquisa, tendo como objetivo contribuir para o seu esclarecimento. Portanto, o problema é uma interrogação que o pesquisador faz à realidade que deve orientar a pesquisa, em que tais referências permitirão situar com maior clareza as contribuições pretendidas.

\section{ELEMENTOS DE ORGANIZAÇÃO DO PROJETO DE PESQUISA}

A Introdução e/ou apresentação do projeto, apesar de ser um item que deve estar disposto no início do trabalho, só é redigido no final, quando os demais itens já tiverem prontos. Isto por que a introdução é a parte do projeto onde se faz uma breve apresentação do tema, ou seja, é a explicação de como se chegou a um questionamento e do motivo pelo qual há uma curiosidade a respeito do tema que se propõe pesquisar. Nela pode conter um breve histórico sobre o tema a ser pesquisado. É importante que seja um texto que tenha bastante clareza e objetividade, facilitando a compreensão do leitor quanto aos aspectos essenciais do tema.

Continuando, segue a justificativa que é um elemento importante para um projeto de pesquisa, pois ressalta a relevância do assunto, explicitando-se os motivos de ordem teórica e prática que justificam a pesquisa, evidenciando contribuição do projeto para o conhecimento e para a sociedade, visando explicar as razões de ordem pessoal para se realizar a pesquisa, ou seja, responde ao "por que fazer", se atendo para as seguintes relevâncias: científica, social e viabilidade.

Já nos objetivos, apresentam-se as metas que se pretende atingir, formulando suas pretensões, definindo, esclarecendo e revelando os focos de interesse da pesquisa, lembrando que os objetivos se dividem em dois: geral, que se relaciona diretamente ao problema direcionando o foco central da pesquisa de maneira ampla em que o pesquisador pretende obter uma resposta satisfatória ao problema levantado. Os objetivos específicos apresentam o caráter mais concreto da pesquisa, ou seja, conduzirão o desfecho para 
o alcance do objetivo geral e são formulados sempre, mediante o emprego dos verbos no infinitivo.

Na sequência, vêm as hipóteses que são respostas provisórias ao problema da pesquisa. É uma proposição que pode ser colocada prova para determinar a sua validade, lembrando que ela pode ser aceita ou rejeitada depois de investigada.

Na Fundamentação Teórica, é o momento da pesquisa em que se irá definir a concepção teórica a ser utilizada e os conceitos fundamentais que serão utilizados, os experimentos, o avanço da ciência nesta área. Nesse item, podem-se comentar trabalhos já feitos, salientando a contribuição dos mesmos para a proposta da pesquisa. Enfim busca-se uma fundamentação por meio de um arcabouço bibliográfico, analisam-se as mais recentes obras científicas disponíveis que tratem do assunto ou que deem embasamento teórico e metodológico para o desenvolvimento do projeto de pesquisa.

A metodologia é o conjunto de métodos e técnicas utilizados para a realização de uma pesquisa, nela deve conter um conjunto de atividades organizadas para levantamento dos dados para a realização da pesquisa, assim como, deverão ser listados todos os procedimentos e métodos necessários para testar suas hipóteses e alcançar os objetivos propostos. Os métodos de pesquisa e sua definição dependem do objeto e do tipo da pesquisa, não se esquecendo de que nesta parte deverá ser indicado o tipo de pesquisa a ser realizada, as amostragens, o local, os elementos relevantes, o material a serem utilizados como será feito a coleta de dados e análise dos resultados, enfim, tudo que for necessário para concretização da pesquisa.

O cronograma se faz necessário para cronometrar o tempo das atividades que serão realizadas durante o procedimento da pesquisa, em que se expressa a compatibilização das atividades propostas com o tempo previsto para a realização do projeto como um todo. Esse processo deverá ser divido em etapas, devendo indicar o início e fim de cada etapa, ou seja: planejamento, execução e divulgação. É uma etapa importante em que permitirá os pesquisadores avaliarem continuamente o andamento do projeto e o acompanhamento do tempo disponível.

O orçamento é o item que está relacionado aos recursos financeiros a serem utilizados ao longo de todo o projeto.

A referência bibliográfica como elemento pós-textual, é a representação dos documentos efetivamente citadas e consultadas para realização do projeto, ou seja, onde deverá relacionar as fontes consultadas e referenciadas, devendo obedecer as normas da ABNT-NBR6023. Apêndice: elementos complementares ao projeto que foram elaborados pelo pesquisador. (Ex: questionários, formulários de pesquisa de campo ou fotografias). Devem ser incluídos somente se extremamente necessários. Os anexos, também, só devem aparecer nos projetos de pesquisa se forem extremamente necessários. São textos de autoria de outra pessoa e não do pesquisador. Por exemplo: mapas, documentos originais, fotografias tiradas por outra pessoa que não o pesquisador.

Vale relembrar que um projeto de pesquisa não necessita ser volumoso, tem que ter concisão na apresentação das ideias, transformando-as num planejamento adequado. O importante é que seja uma proposta clara e coerente. Complementando, qualquer tipo de pesquisa, individual ou coletiva, sem aprovação de um CEP não tem validade científica, uma vez que estão ausentes os princípios da ética em pesquisa (normas) e o correto exercício da profissão. 


\section{PROJETO DE PESQUISA NO ÂMBITO UNIVERSITÁRIO}

Em relação à importância do projeto de pesquisa, cumpre ressaltar que se trata de um trabalho intelectual que requer do autor, domínio do conteúdo a ser abordado, tendo como principal finalidade, servir de instrumento norteador de orientação que visa ao acompanhamento das atividades realizadas pelo autor, bem como ferramenta de apoio para a aquisição de financiamento de pesquisa científica, quando da solicitação a órgão especifico e ainda, como diretriz na organização de uma investigação científica.

\subsection{GRADUAÇÃO}

O grande desafio da universidade hoje é formar indivíduos capazes de buscar conhecimentos e de saber utilizá-los, encontrando por meio da pesquisa, respostas para suas dúvidas. Segundo (LOMBARDI, 2000), "o graduando ao ingressar na universidade depara-se com duas situações: ser acadêmico e ter que fazer ciência“, é por meio da inserção do aluno de graduação na iniciação científica que se descobre as qualidades de um bom pesquisador, aprendendo a buscar o conhecimento, lidando com o desconhecido para se chegar a novos conhecimentos.

\subsubsection{INIIIAÇÃO CIENTÍFICA}

A iniciação científica tem como principal finalidade agregar professores, alunos e disciplinas com afinidades, visando ao desenvolvimento intelectual, bem como habilidades e competências. Nessa seara, tem destaque o orientador, por várias razões. Primeiramente pela sua experiência acadêmica e vivência intelectual e em segundo lugar, pelo aprendizado dispensado ao aluno, oportunidade de aprimoramento do conhecimento no que concerne à pesquisa científica. Igualmente, pelas novas contribuições essenciais e concretas oriundas da atividade de construção do conhecimento que rompem com o discurso da aula expositiva (CASTRO, 2012). Nesse contexto, exige-se a elaboração de um projeto de pesquisa quando do momento da inscrição em um programa dessa natureza.

\subsubsection{PROGRAMAS DE INICIAÇÃO CIENTÍFICA}

Concedida pelo $\mathrm{CNPq}$ desde sua fundação em 1951, a bolsa de Iniciação Científica é uma modalidade que tem como principal objetivo "despertar jovens talentos para a ciência. Ao longo do tempo, os objetivos dessa modalidade foram ampliados e diversificados" (CNPQ, 2013, [n.p.]).

Nos dias atuais,

[a] Iniciação Científica é concedida por meio de programas institucionais via Chamadas Públicas de propostas lançadas periodicamente. Atualmente, existem os programas institucionais de iniciação científica, cuja concessão são feitas às instituições que se candidatampor meio de Chamadas Públicas de propostas lançadas periodicamente (CNPQ, 2013, [n.p.]).

Em geral, são programas institucionais que visam aos estudantes do Ensino Superior, sendo eles: "PIBIC, o PIBIC-Af, o PICME e o PIBITI. Os programas voltados para os estudantes do Ensino Médio e Fundamental são: a PIC-OBMEP, o IC-Jr/FAPs e o PIBIC-EM" (CNPQ, 2013, [n.p.]). Em suas abordagens, esses programas se caracterizam das seguintes formas:

1. O PIBIC foi o primeiro programa institucional criado para a Iniciação Científica. O Programa atende instituições de Ensino e/ou Pesquisa públicas e privadas. As cotas de Iniciação Científica são concedidas diretamente às Instituições por meio de Chamada Pública de propostas. A seleção dos projetos é feita pelas instituições.

2. O PIBITI é um programa institucional voltado para a 
Iniciação Tecnológica e de Inovação de estudantes de graduação. O Programa concede bolsas de Iniciação Científica às instituições que desenvolvem pesquisa em tecnologia e inovação por meio de Chamada Pública de propostas. A seleção dos projetos é feita pelas instituições (CNPQ, 2013, [n.p.]).

\section{Complementando, são destaques, também:}

3. O PIBIC-Af é o programa institucional de Iniciação Científica nas Ações Afirmativas, resultado de uma parceria entre CNPq e SEPPIR. O Programa concede bolsas de IC diretamente para as Instituições Públicas, participantes do PIBIC e que tenham implementado ações afirmativas para o ingresso no Ensino Superior. Somente poderão ser indicados os estudantes que sejam beneficiários de ações afirmativas. A seleção dos projetos é feita pelas instituições.

4. O PICME é o programa de Iniciação Científica e Mestrado desenvolvido em parceria com a Capes e com o IMPA. As bolsas de Iniciação Científica são concedidas aos medalhistas da Olimpíada Brasileira de Matemática nas Escolas Públicas (OBMEP) ou da Olimpíada Brasileira de Matemática (OBM) que estejam cursando a graduação. A indicação dos bolsistas é feita pelo IMPA (CNPQ, 2013, [n.p.]).

Igualmente, destacam-se ainda, outros programas de igual relevância, como:

5. O PIBIC-EM é o programa institucional de Iniciação Científica voltado para estudantes do Ensino Médio. As bolsas de IC-Jr são concedidas diretamente às Instituições. Somente poderão ser beneficiários os estudantes que estiverem cursando o Ensino Público.

6. O PIC-OBMEP é o programa de Iniciação Científica desenvolvido em parceria com o IMPA nos Ensinos Fundamental e Médio. As bolsas de IC-Jr são concedidas aos premiados na Olimpíada Brasileira de Matemática nas Escolas Públicas (OBMEP). A indicação dos bolsistas é feita pelo IMPA.

7. O IC-Jr/FAPs é o programa de Iniciação Científica desenvolvido em parceria com as Fundações de Apoio à Pesquisa voltado para os estudantes de Ensino Médio das escolas públicas. As cotas são concedidas às FAPs que fazem a seleção dos projetos e indicação dos bolsistas.
Assim, o estudante de graduação encontra nessas modalidades inúmeras oportunidades de desenvolver uma pesquisa científica, amparada legalmente por esses programas. Para tanto, necessita ter em mãos o projeto de pesquisa, ou seja, o roteiro de sua realização, em conformidade com a normalização vigente a sua elaboração.

\subsection{PÓS-GRADUAÇÃO}

Na pós-graduação, continuidade da jornada acadêmica do ensino superior, prevalece à formação de profissionais competentes e excelentes pesquisadores, compromissados com o desenvolvimento científico e tecnológico, respaldado na questão social. Nessa abordagem, ressalta-se que,

[...] [a] crescente integração entre as principais agências de fomento à pesquisa e pós-graduação no Brasil, associada à definição de uma política nacional de ciência e tecnologia nas várias áreas do conhecimento, impõe a necessidade de reavaliar os critérios de acompanhamento e avaliação na pós-graduação (PG). Além da produção intelectual, devem ser valorizados indicadores de medida do impacto social do conhecimento produzido nos cursos de pós-graduação. 0 envolvimento ativo de usuários com produtores do conhecimento, na elaboração integrada de planos nacionais de pós-graduação e conferências nacionais de ciência, tecnologia e inovação, pode contribuir para um melhor direcionamento social das ações científicas adequadas à realidade brasileira (DANTAS, 2004, p. 160).

Nesse âmbito a Coordenação de Aperfeiçoamentode Pessoal de Nível Superior (CAPES) é o órgão responsável pela regulamentação e avaliação constante da pós-graduação brasileira, visando ao direcionamento satisfatório da política desse nível no país, com destaque para os cursos de mestrado e doutorado. Em sua abordagem, contempla desde a organicidade entre linhas de pesquisa, projetos de pesquisa,estrutura curricular, publicações até as dissertações e teses (HORTA; MORAES, 2005). Ressalta-se que em alguns casos o projeto de pesquisa assume o papel de documento primordial para a inscrição em cursos desse nível, bem como de ferramenta eliminatória ao pleiteante. 


\subsubsection{PROGRAMAS DE PÓS-GRADUAÇÃO}

No Brasil, a Coordenação de Aperfeiçoamento de Pessoal de Nível Superior (CAPES), concede bolsas de estudo, visando "estimular a formação de recursos humanos de alto nível, consolidando assim os padrões de excelência imprescindíveis ao desenvolvimento do nosso país" (CAPES, 2013, [n.p.]). Isso só é possível, pelo fato de que esse órgão do Governo Federal mantém os seguintes programas:

DINTER Novas Fronteiras

Programa de formação, em nível de doutorado no país, dos docentes das Instituições de Ensino Superior (IES), federais ou estaduais, pertencentes às regiões Norte, Nordeste ou Centro-Oeste.

Programa de Demanda Social (DS) e Programa de Apoio à Pós-Graduação (PROAP)

Concede bolsas a cursos de pós-graduação stricto sen$s u$ (mestrado e doutorado). MINTER e DINTER - CAPES/SETEC

Programa de formação, em nível de pós-graduação stricto sensu no país, dos integrantes do quadro de pessoal permanente das Instituições de Ensino Superior (IES) pertencentes à Rede Federal de Educação Profissional, Científica e Tecnológica.

Programa de Apoio a Eventos no País (PAEP)

Concede recursos a eventos de caráter científico, tecnológico e cultural de curta duração(CAPES, 2013, [n.p.] grifo do autor).

Como, também, programas que tratam da qualificação docente no mais alto grau:

Programa Institucional de Qualificação Docente para a Rede Federal de Educação Profissional e Tecnológica (PIQDTEC)

Apóia a formação, em nível de pós-graduação stricto sensu no país, de docentes e técnicos administrativos em educação da Rede Federal de Educação Profissional, Científica e Tecnológica (RFEPT).

Plano Nacional de Pós-Doutorado (PNPD)

O edital do Programa Nacional de Pós-Doutorado (PNPD) deve integrar pesquisas desenvolvidas entre universidades e empresas. Uma das ações do Plano de
Desenvolvimento da Educação (PDE), o programa estimula a atuação de recém-doutores em projetos de desenvolvimento científico em áreas estratégicas, a formação de recursos humanos e a inovação tecnológica. Programa de Apoio a Projetos Institucionais com a Participação de Recém-Doutores (PRODOC)

Complementa a formação de recém-doutores, estimulando o desenvolvimento de projetos institucionais e a melhoria do desempenho dos programas brasileiros de pós-graduação.

Programa de Formação Doutoral Docente (PRODOUTORAL)

Programa de formação, em nível de doutorado no país, dos docentes das Instituições Federais de Ensino Superior (IFES) que favorece a mobilidade dos bolsistas e seus orientadores (CAPES, 2013, [n.p.] grifo do autor).

E ainda, aqueles relativos a Pró-Reitora de Extensão Acadêmica e destinados a professores visitantes, conforme seguem:

Programa de Excelência Acadêmica (Proex)

Mantém o padrão de qualidade dos programas de pós-graduação com nota 6 ou 7.

Programa de Suporte à Pós-Graduação de Instituições de Ensino Particulares (PROSUP)

Apóia a pós-graduação stricto sensu (mestrado e doutorado) das instituições de ensino superior particulares. Programa Professor Visitante Nacional Sênior (PVNS)

Programa de apoio à consolidação das Instituições Federais de Ensino Superior (IFES) criadas a partir do ano 2000, bem como daquelas participantes do programa REUNI, com campi fora de sede.

Programa Professor Visitante Sênior (PVS Capes-UNILA) Programa de apoio à consolidação da estrutura acadêmica da Universidade Federal da Integração Latino-Americana (UNILA).

Além destes, a CAPES também concede bolsas de estudos no exterior, com o intuito de fomentar a pesquisa em outros meios acadêmicos, por intermédio de recursos humanos de alto nível. Em todos os níveis e graus, contempla-se a elaboração do projeto de pesquisa como elemento de referência para o pleiteante a uma vaga em cursos de pós-graduação. 


\section{CONCLUSÂO}

Assim, conclui-se que o projeto de pesquisa tem como elemento crucial a investigação científica, a necessidade de um empreendimento ou de um processo de elaboração, a execução do projeto de pesquisa, o domínio das técnicas e normas que levarão o pesquisador a adquirir uma atitude científica.

Para um estudo eficaz, o projeto de pesquisa se faz presente ao longo do processo acadêmico, isso proporciona o aprimorando e a percepção, ampliando os horizontes de compreensão. Nesse sentido, vislumbra-se que por representar apenas a parte formal inicial de uma pesquisa de cunho científico, o projeto de pesquisa é responsável por mediar às dúvidas do pesquisador elencando as informações que se pode construir a partir da realidade.

Desse modo, há a necessidade de elaboração de projetos científicos para que toda a comunidade acadêmica, como também a sociedade em geral se desenvolvam e tomem conhecimentos de fatos diversos, incorporando o espírito investigativo em qualquer área do conhecimento. Nota-se, também, a relevância da iniciação científica do acadêmico, apontando, que o início do saber científico é a sistematização do conhecimento.

\section{REFERÊNCIAS}

ABNT. Associação Brasileira de Normas Técnicas. NBR 15287: Informação e documentação - Projeto depesquisa - Apresentação. 2006. Disponível em: <http://www. ueap.ap.gov.br/concursos/pibic2/normas/15287_2005. pdf>. Acesso em: 10 fev. 2013.

CASTRO, César Augusto. A pesquisa discente nos cursos de graduação em biblioteconomia e ciência
Nesse sentido, ele deve-se ater às diretrizes pré-definidas que contém os elementos fundamentais para uma boa execução da pesquisa, que em se tratando de um trabalho intelectual, de uma dúvida e o seu aprimoramento na forma de Projeto. Assim, este artigo, na condição de apresentar procedimentos e etapas para elaboração do Projeto de Pesquisa, reafirma a importância do mesmo para a continuidade da vida acadêmica dos estudantes, tanto quanto, para o sucesso de suas vidas profissionais.

As instituições de ensino superior são as grandes encaminhadoras dessas atividades, elaboram planos que devem ser seguidos durante a investigação, encaminham e acompanham todos os trabalhos dos discentes. Outra ação indispensável ao processo, e que também é realizada por estas instituições é a vinculação da pesquisa a Associação de Normas Técnicas (ABNT).

Também se percebe que o trabalho de pesquisa é algo a ser amplamente realizado, tanto na graduação, quanto na Pós-graduação, por professores e alunos. Outra informação que confirma a necessidade do projeto de pesquisa é o crescente incentivo e atenção que estão sendo dispensados para que o número de trabalhos, a serem desenvolvidos, se amplie de forma significativa nas universidades.

da informação. Transinformação, v.14, n.1, p.49-53, jan.- jun., 2002. Disponível em: <http://periodicos. puc-campinas.edu.br/seer/index.php/transinfo/article/viewFile/1506/1480>. Acesso em: 20 abr. 2013.

COOPER, Donald R.; SCHINDLER, Pamela S. Métodos de pesquisa em administração. 7. ed. Porto Alegre: Bookman, 2003. 
CNPQ. Conselho Nacional de Desenvolvimento Científico e Tecnológico. Programas institucionais de iniciação científica e tecnológica. Disponível em:<http://www.cnpq.br/web/guest/piict>. Acesso em: 25 mar. 2013.

CAPES. Conselho de Aperfeiçoamento de Pessoal de Nível Superior. Bolsas no País. Disponível em:<http:// www.capes.gov.br/bolsas/bolsas-no-pais>. Acesso em: 25 mar. 2013.

DANTAS, Flávio. Responsabilidade social e pós-graduação no Brasil: idéias para (avali)ação. Experiências. RBPG, v. 1, n. 2, p. 141-159, nov. 2004. Disponível: <http://www2.capes.gov.br/rbpg/images/stories/downloads/RBPG/Vol.1_2_nov2004_/160_172_responsabilidadesocial_posgraduacao_brasil.pdf>. Acesso em: 12 mar. 2013.

\section{GIL. Antônio Carlos. Como elaborar projetos de pes-} quisa. São Paulo: Atlas, 2002.

HORTA, José Silvério Baía; MORAIS, Maria Célia Marcondes de. 0 sistema CAPES de avaliação da pós-graduação: da área de educação à grande área de ciências humanas. Revista Brasileira de Educação. Set., out., nov., dez. 2005, n. 30. Disponível em: <http:// www.scielo.br/pdf/\%0D/rbedu/n30/a08n30.pdf>. Acesso em: 22 abr. 2013.

LOMBARDI, J.C. (Org.). Pesquisa em educação: história, filosofia e temas transversais. 2. ed. Campinas: Autores Associados/ Caçador: HISTERDBR-UnC, p.95-104, 2000. Disponivel em: <http://www.efdeportes.com/efd123/ metodologia-cientifica-construcao-da-pesquisa-em-educacao-fisica.htm>. Acesso em: 18 fev. 2013. 